\title{
Overexpression of $\mathbf{G}$ protein-coupled receptor 87 correlates with poorer tumor differentiation and higher tumor proliferation in non-small-cell lung cancer
}

\author{
KAZUHITO NII $^{1}$, YOSHIMASA TOKUNAGA ${ }^{1}$, DAGE LIU ${ }^{1}$, XIA ZHANG $^{2}$, JUN NAKANO $^{1}$, \\ SHINYA ISHIKAWA ${ }^{1}$, YOSHIYUKI KAKEHI ${ }^{2}$, REIJI HABA ${ }^{3}$ and HIROYASU YOKOMISE ${ }^{1}$ \\ Departments of ${ }^{1}$ General Thoracic Surgery, Breast and Endocrinological Surgery, ${ }^{2}$ Urology and ${ }^{3}$ Pathology, \\ Faculty of Medicine, Kagawa University, Miki, Kagawa 761-0793, Japan
}

Received November 18, 2013; Accepted April 29, 2014

DOI: $10.3892 / \mathrm{mco} .2014 .292$

\begin{abstract}
G protein-coupled receptor 87 (GPR87) is a newly deorphanized member of the transmembrane $G$ protein-coupled receptor family. Recently, GPR87 was suggested to contribute to the viability of human tumor cells and overexpression of GPR87 mRNA was detected in a number of malignant tumors, including lung cancer. We performed a retrospective study of GPR87 expression in association with clinical characteristics and biological markers in non-small-cell lung cancer (NSCLC). We investigated a total of 123 patients with NSCLC who underwent surgery between 1999 and 2004 (58 adenocarcinomas, 53 squamous cell carcinomas and 12 others). Immunohistochemistry was used to evaluate the intratumoral expression of GPR87 and the Ki-67 proliferation index. The TUNEL method was also used to investigate tumor apoptosis. A total of 63 tumors (51.2\%) were found to be GPR87-positive. These tumors were more frequently encountered among squamous cell carcinomas rather than among adenocarcinomas ( 62.3 vs. $43.1 \%$, respectively; $\mathrm{P}=0.044$ ) and were significantly more frequently poorly and moderately differentiated rather than well differentiated $(\mathrm{P}=0.029)$. Moreover, the Ki-67 index was significantly higher in GPR87-positive compared to GPR87-negative tumors ( 57.0 vs. $40.0 \%$, respectively; $\mathrm{P}=0.002$ ). The overall survival was significantly worse for patients with GPR87-positive compared to those with GPR87-negative tumors $(\mathrm{P}=0.029)$. The Cox regression analyses also demonstrated that the GPR87 status was a significant prognostic factor for NSCLC patients [hazard ratio $=2.053 ; \mathrm{P}=0.018$ ). The present study demonstrated that in NSCLC, the overexpression of GPR87 is significantly associated with poorer differentiation
\end{abstract}

Correspondence to: Dr Dage Liu, Department of General Thoracic Surgery, Breast and Endocrinological Surgery, Faculty of Medicine, Kagawa University, 1750-1 Ikenobe, Miki-cho, Kita-gun, Kagawa 761-0793, Japan

E-mail: dgliu@kms.ac.jp

Key words: G protein-coupled receptor 87, non-small-cell lung cancer, differentiation, proliferation, survival, prognostic factor and higher proliferation. During the progression of NSCLC, GPR87 overexpression may be associated with the acquisition of a more aggressive phenotype and, therefore, is a potentially useful target for prognostication and treatment.

\section{Introduction}

Lung cancer has a poor prognosis and remains the leading cause of cancer-related mortality worldwide (1). Approximately $85 \%$ of newly diagnosed lung cancers are non-small-cell lung cancer (NSCLC), which includes three cell types (adenocarcinoma, squamous cell and large-cell carcinoma); these types may be further divided into various subtypes or variants. Although significant advances have been made in the treatment of NSCLC with the use of molecular-targeted therapies, such as the epidermal growth factor receptors (EGFR)-specific tyrosine kinase inhibitors, gefitinib and erlotinib, the median overall survival for patients with advanced NSCLC treated with EGFR-targeting agents averages only 24 months (2). Furthermore, such therapy is ineffective for squamous cell lung cancer; therefore, novel therapies are required to improve the overall clinical outcome of NSCLC patients.

The $\mathrm{G}$ protein-coupled receptor (GPCR) family is one of the largest receptor families with $>800$ members, known since the human genome sequencing project (3). GPCRs each contain a seven-membrane spanning helix connected by 3 intracellular loops with an extracellular $\mathrm{NH}_{2}$ terminus and an intracellular $\mathrm{COOH}$ terminus (4). GPCRs are widely expressed in human tissues and are involved in a wide range of physiological functions. In addition, GPCRs are often relevant in the context of disease and are targeted, directly or indirectly, by 50-60\% of currently available therapeutic agents (4). Moreover, the overexpression of several GPCRs was demonstrated in tumor tissues and GPCR signaling was reported to promote cell growth and survival, angiogenesis, metastasis and drug resistance (5).

G protein-coupled receptor 87 (GPR87) was a GPCR orphan receptor $(6,7)$ that was recently deorphanized as a lysophosphatidic acid receptor (8). Functionally, GPR87 has been reported to contribute to the viability of human tumor cells (9), as it is required for p53-dependent cell survival in 
response to genotoxic stress (10). The use of different mRNA expression databases, including laser-capture microdissected tissue samples and immunohistochemistry using a panel of human tumors, have revealed tumor-specific overexpression of GPR87 mRNA in a number of human tumors, including lung cancer (9). However, the functional role of GPR87 has not been well documented and the number of available clinical studies is currently limited. Therefore, we conducted the present retrospective study on GPR87 expression in association with clinical characteristics and biological markers in a series of NSCLCs.

\section{Materials and methods}

Clinical characteristic of NSCLC patients. We investigated consecutive NSCLC patients who underwent surgery at the Department of General Thoracic Surgery of Kagawa University between June, 1999 and July, 2004. All the patients provided written informed consent. The patients were aged 44-84 years, with a mean age of 71 years. Tumor-node-metastasis staging designations were performed according to the postoperative pathological international staging system (11). The selected samples were not biased by age, gender or pathological stage. The patients who had been determined as having no residual tumor in the resected specimen following surgery were excluded. A total of 123 patients with NSCLC up to stage IIIB, including 58 patients with adenocarcinoma, 53 with squamous cell carcinoma and 12 with other types of NSCLC (7 with adenosquamous cell carcinoma and 5 with large-cell carcinoma) were finally investigated (Table I). The clinical records and histopathological diagnoses of the patients were fully documented. Recently, a difference has emerged in the selection of pre- or postoperative chemotherapy between adenocarcinoma and squamous cell carcinoma with the advent of molecular-targeted drugs and novel anticancer agents, which may affect prognosis. For this reason, we selected samples collected prior to the advent of new drugs. This study includes follow-up data as of December 2012. The median follow-up period for all the patients was $77.4 \pm 42.7$ months. This study was approved by the Institutional Review Board of Kagawa University.

Immunohistochemistry. Immunohistochemistry was used to evaluate the intratumoral expression of GPR87 and tumor proliferation rate using the $\mathrm{Ki}-67$ index. The following antibodies were used, along with isotype antibodies as negative controls: a rabbit polyclonal antibody for GPR87 (LS-A1584; LSBio, Seattle, WA, USA) at a dilution of 1:500 and a mouse monoclonal antibody for the Ki-67 antigen (MIB-1; DakoCytomation, Glostrup, Denmark) at a dilution of 1:40.

Formalin-fixed paraffin-embedded tissue was cut into $4-\mu \mathrm{m}$ sections and mounted on poly-L-lysine-coated slides (Muto Pure Chemicals Co. Ltd, Tokyo, Japan). The sections were deparaffinised and rehydrated. The slides were then heated in a microwave for $20 \mathrm{~min}$ in a $10 \mu \mathrm{mol} / 1$ citrate buffer solution ( $\mathrm{pH}$ 6.0) and cooled to room temperature. After quenching the endogenous peroxidase activity with $0.3 \% \mathrm{H}_{2} \mathrm{O}_{2}$ (in absolute methanol) for $30 \mathrm{~min}$, the sections were treated for $2 \mathrm{~h}$ with $5 \%$ bovine serum albumin (Sigma-Aldrich, Tokyo, Japan) at room temperature to block non-specific staining. The sections were incubated overnight with the primary specific antibodies.
Table I. Distribution of GPR87 status in 123 NSCLC patients according to clinical characteristics.

\begin{tabular}{|c|c|c|c|c|}
\hline \multirow[b]{2}{*}{ Variables } & \multirow[b]{2}{*}{ No. } & \multicolumn{2}{|c|}{ GPR87 status } & \multirow[b]{2}{*}{ P-value } \\
\hline & & Negative & Positive & \\
\hline Gender & & & & 0.330 \\
\hline Male & 89 & 41 & 48 & \\
\hline Female & 34 & 19 & 15 & \\
\hline Smoking status & & & & 0.120 \\
\hline Never & 37 & 22 & 15 & \\
\hline Former/present & 86 & 38 & 48 & \\
\hline Histology & & & & 0.044 \\
\hline Adenocarcinoma & 58 & 33 & 25 & \\
\hline Squamous cell carcinoma & 53 & 20 & 33 & \\
\hline Other & 12 & 7 & 5 & \\
\hline Differentiation & & & & 0.029 \\
\hline High & 34 & 22 & 12 & \\
\hline Moderate and poor & 89 & 38 & 51 & \\
\hline Tumor status & & & & 0.863 \\
\hline $\mathrm{T} 1$ & 56 & 25 & 31 & \\
\hline $\mathrm{T} 2$ & 42 & 22 & 20 & \\
\hline $\mathrm{T} 3$ & 13 & 7 & 6 & \\
\hline $\mathrm{T} 4$ & 12 & 6 & 6 & \\
\hline Nodal status & & & & 0.373 \\
\hline NO & 89 & 42 & 47 & \\
\hline N1 & 17 & 9 & 8 & \\
\hline $\mathrm{N} 2$ & 16 & 8 & 8 & \\
\hline N3 & 1 & 1 & 0 & \\
\hline Pathological stage & & & & 0.844 \\
\hline I & 70 & 33 & 37 & \\
\hline II & 25 & 12 & 13 & \\
\hline III & 28 & 15 & 13 & \\
\hline Total number & 123 & 60 & 63 & \\
\hline
\end{tabular}

GPR87, G protein-coupled receptor 87; NSCLC, non-small-cell lung cancer.

The slides were then incubated for $1 \mathrm{~h}$ with biotinylated secondary antibodies (Vector Laboratories, Burlingame, CA, USA). Subsequently, the sections were incubated with the avidin-biotin-peroxidase complex (Vector Laboratories) for $1 \mathrm{~h}$ and antibody binding was visualized with 3,3'-diamionbenzidine tetrahydrochloride. Finally, the sections were lightly counterstained with Mayer's hematoxylin. Sections of lung tumors known to express GPR87 were used as positive controls.

All the immunostained sections were reviewed by two authors (K.N. and D.L.) who were blinded to the patients' characteristics. Cases with discrepancies were jointly reevaluated until a consensus was reached. GPR87 expression in the tumors was analyzed using a histological semi-quantitative scoring (H-score) method, as previously described (12). The percentage of carcinoma cells exhibiting positive staining for $\mathrm{Ki}-67$ in a given specimen was scored as the Ki-67 proliferation index. 
A
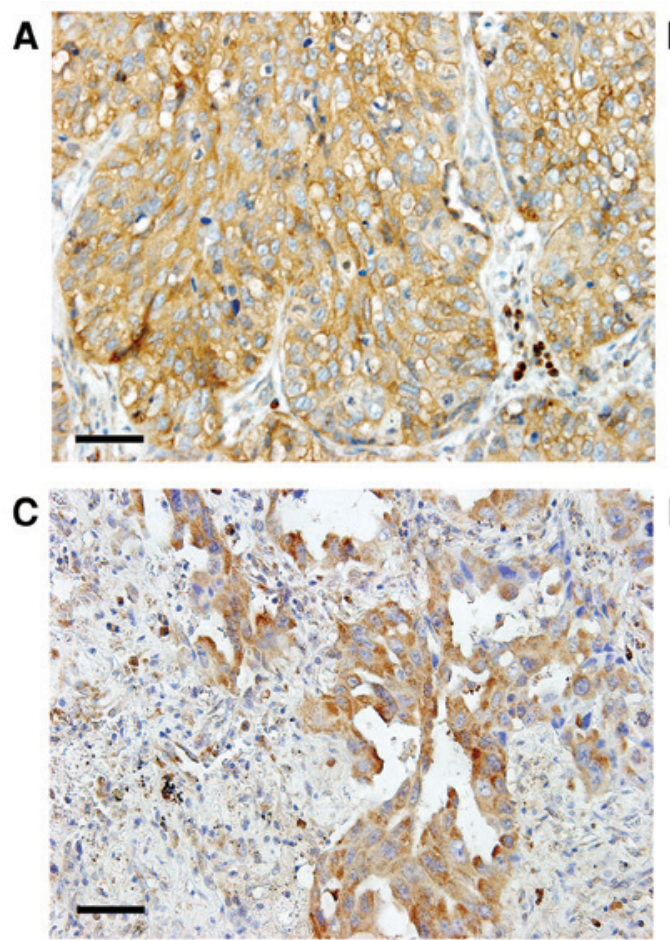
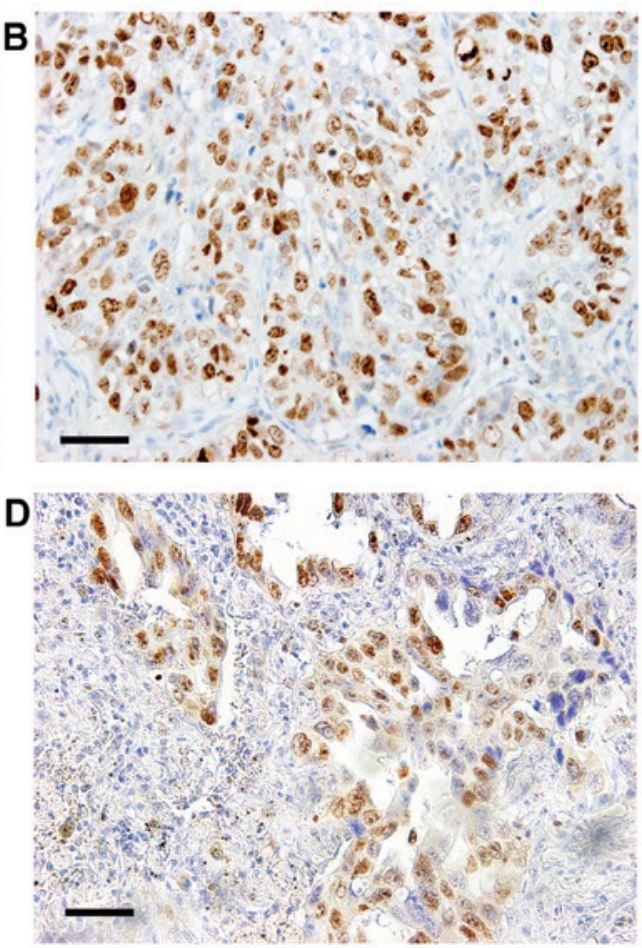

Figure 1. Representative images of immunohistochemistry. (A) GPR87 positivity in squamous cell carcinoma; (B) Ki-67 positivity in squamous cell carcinoma; (A) and (B) are serial sections from the same tumor. (C) GPR87 positivity in adenocarcinoma; (D) Ki-67 positivity in adenocarcinoma. (C) and (D) are serial sections from the same tumor. GPR87, G protein-coupled receptor 87.

TUNEL method for apoptosis. Detection of apoptotic cells was performed with the TUNEL method, as described by Sgonc and Wick (13). The TUNEL staining was performed using the In Situ Detection kit (Takara Bio, Inc., Otsu, Shiga, Japan) according to the manufacturer's protocol. For apoptotic detection, a total of 10,000 tumor cells (1,000 tumor cells per field in 10 different fields) were evaluated at high magnification (x400). The apoptotic index was defined as the number of apoptotic cells per 1,000 tumor cells.

Statistical analysis. The median value of the H-score was calculated at 50 and used as a cut-off to select GPR87-positive $(\geq 50)$ and -negative $(<50)$ tumors. The association between GPR87 and several parameters was compared using the Chi-square test or the t-test. The overall survival was defined as the time from treatment initiation (surgical resection, chemotherapy or radiation) to the date of death from any cause. The Kaplan-Meier method was used to estimate the probability of overall survival as a function of time; differences in the survival among patient subgroups were compared using the Mantel's log-rank test. A multivariate and univariate analysis was performed using the Cox regression model to investigate the effects of different variables on survival. All the P-values were based on two-tailed statistical analysis and $\mathrm{P}<0.05$ was considered to indicate a statistically significant difference.

\section{Results}

GPR87 expression in NSCLC. Intratumoral GPR87 expression was displayed as a membranous/cytoplasmic staining pattern and GPR87 expression was found to be low in normal alveolar epithelium (Fig. 1A and C). The H-score of tumor

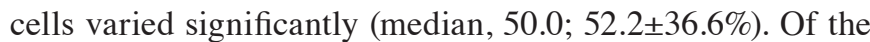
123 NSCLCs, 63 (51.2\%) were GPR87-positive (Table I). GPR87-positive tumors accounted for 33 of the 53 squamous cell carcinomas $(62.3 \%)$ and 25 of the 58 adenocarcinomas (43.1\%), with GPR87-positive tumors being more frequently encountered among squamous cell carcinomas compared to adenocarcinomas $(\mathrm{P}=0.044$, Fig. $2 \mathrm{~A})$. A total of 3 of the 7 adenosquamous carcinomas $(42.9 \%)$ and the 2 large-cell carcinomas $(100 \%)$ were found to be GPR87-positive (data not shown). Moreover, GPR87-positive tumors accounted for 12 of the 34 well differentiated tumors $(35.3 \%)$ and 51 of the 89 moderately and poorly differentiated tumors (57.3\%), with GPR87-positive tumors being more frequently encountered among moderately and poorly differentiated compared to well differentiated tumors ( $\mathrm{P}=0.029$, Fig. $2 \mathrm{~B})$. There was no significant association between GPR87 status and the other patient variables (Table I).

GPR87 expression in association with the Ki-67 proliferation index and the apoptotic index. To elucidate the biological significance of the GPR87 expression in NSCLCs, the Ki-67 proliferation index and the apoptotic index were investigated in association with GPR87 expression.

The Ki-67 proliferation index varied significantly among the 123 NSCLCs (mean, 45.0; 48.7 $\pm 30.2 \%$ ). The Ki-67 proliferation index was $56.9 \pm 28.2 \%$ in GPR87-positive tumors and $40.0 \pm 30.1 \%$ in GPR87-negative tumors and it was significantly higher in GPR87-positive compared to GPR87-negative tumors $(\mathrm{P}=0.002$, Fig. 2C). Furthermore, the areas of the cancer tissue specimens with positive staining against an anti-Ki-67 antibody were identical to those stained with an anti-GPR87 antibody in the majority of the tumors investigated (Fig. 1). 

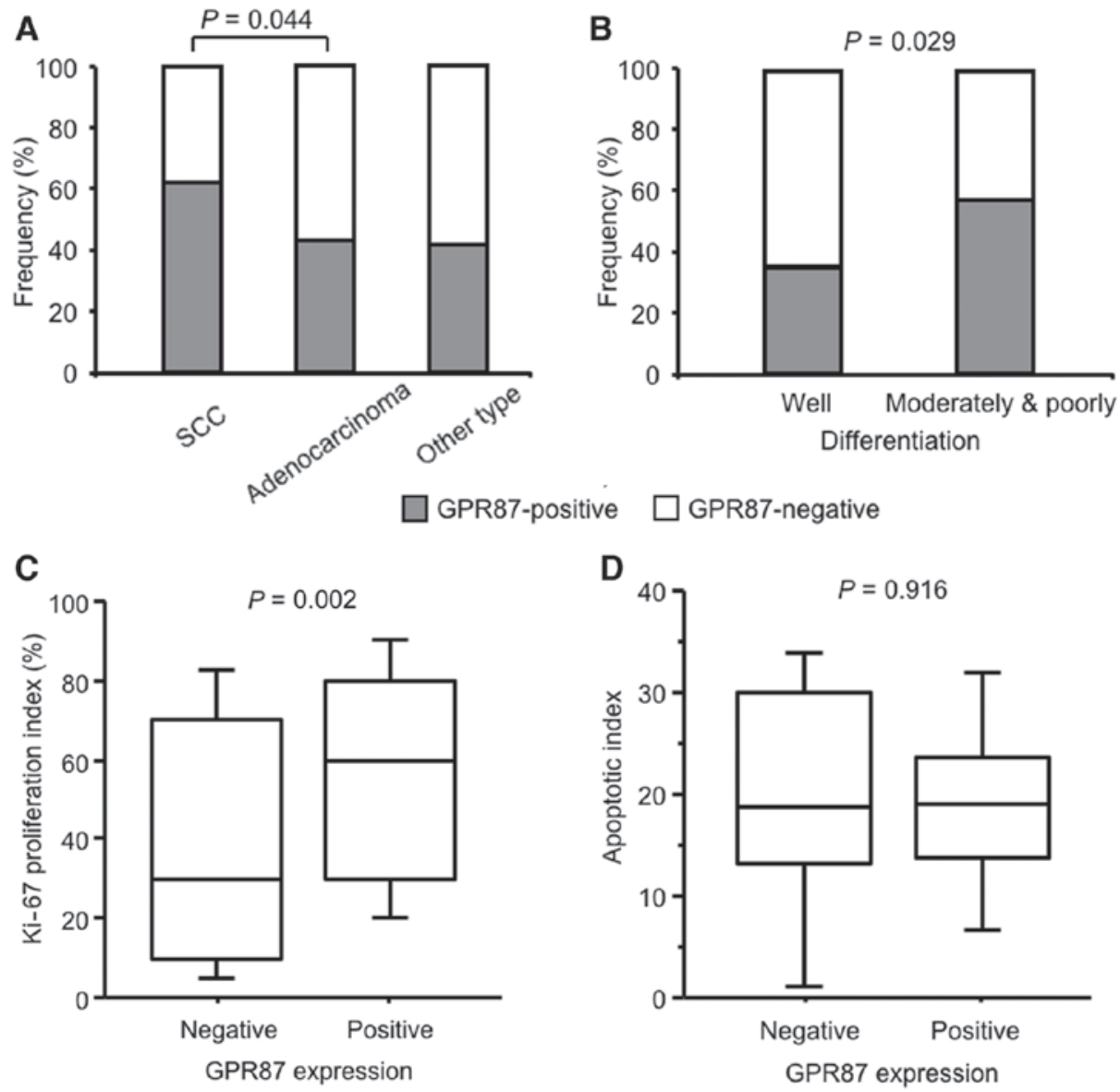

Figure 2. (A) Correlation between GPR87 status and histology. (B) Tumor differentiation in 123 NSCLCs. (C) Ki-67 proliferation index in association with the GPR87 status in NSCLC. (D) Apoptotic index in association with the GPR87 status in NSCLC. SCC, squamous cell carcinoma; GPR87, G protein-coupled receptor 87; NSCLC, non-small-cell lung cancer.
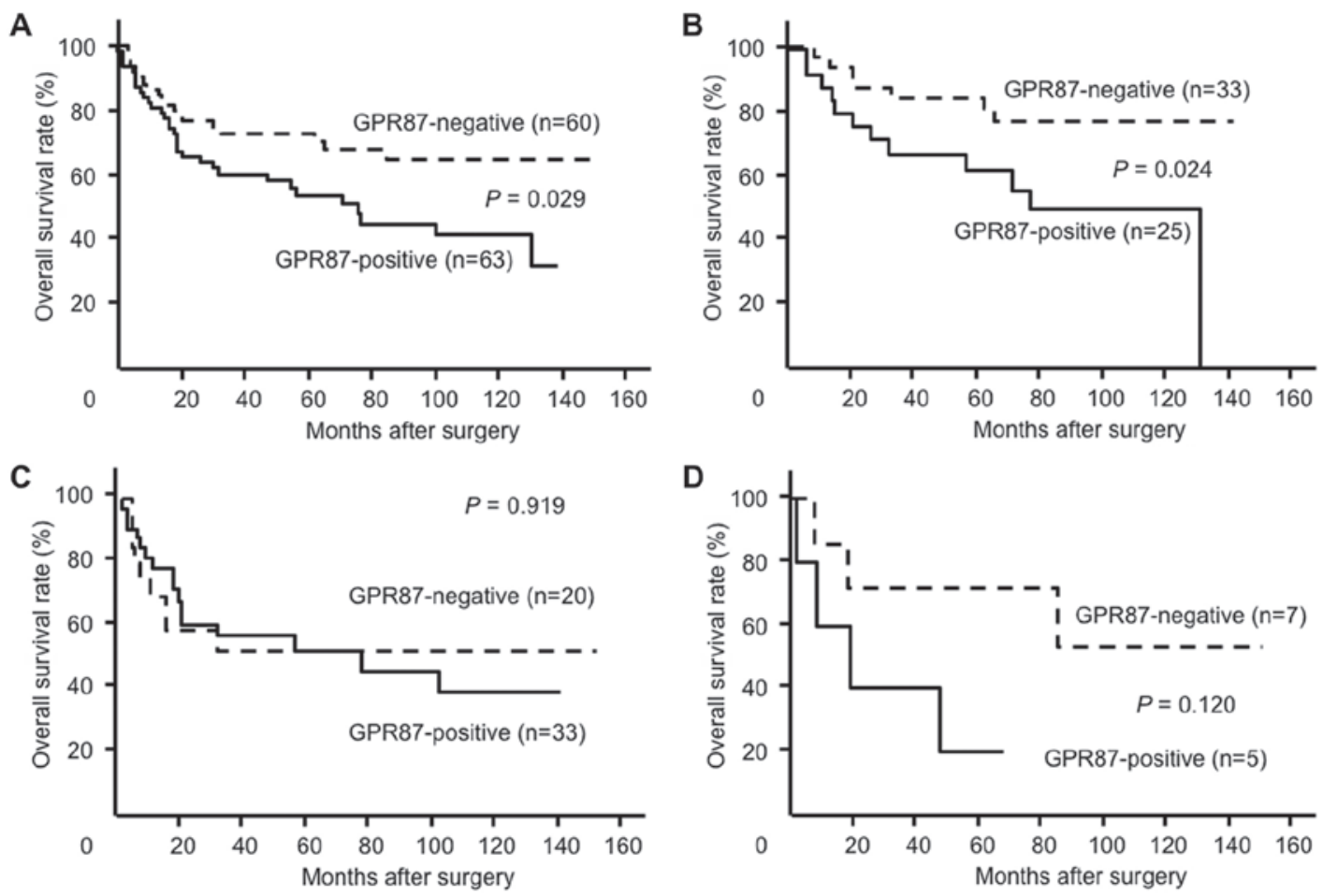

Figure 3. Overall survival of 123 NSCLC patients in association with the GPR87 status. (A) Total number of NSCLC patients (n=123); (B) 59 patients with adenocarcinoma; (C) 55 patients with squamous cell carcinoma; and (D) 12 patients with other histological types of NSCLC. GPR87, G protein-coupled receptor 87; NSCLC, non-small-cell lung cancer. 
Table II. Univariate Cox propotional hazard regression analysis for predicting survival of the 123 NSCLC patients.

\begin{tabular}{lccc}
\hline Variables & HR & $95 \%$ CI & P-value \\
\hline $\begin{array}{l}\text { GPR87 status } \\
\text { Positive/negative }\end{array}$ & 1.859 & $1.052-3.279$ & 0.033 \\
$\begin{array}{l}\text { Age, years } \\
\quad<70 / \geq 70\end{array}$ & 0.833 & $0.479-1.449$ & 0.517 \\
$\begin{array}{l}\text { Smoking status } \\
\text { Former and present/never }\end{array}$ & 1.908 & $0.955-3.817$ & 0.067 \\
$\begin{array}{l}\text { Gender } \\
\quad \text { Male/female }\end{array}$ & 1.712 & $0.896-3.279$ & 0.104 \\
$\begin{array}{l}\text { Differentiation } \\
\text { Poor and moderate/high }\end{array}$ & 1.453 & $0.834-2.532$ & 0.187 \\
$\begin{array}{l}\text { Tumor status } \\
\text { T2-4/T1 }\end{array}$ & 2.812 & $1.535-5.152$ & $<0.001$ \\
$\begin{array}{l}\text { Nodal status } \\
\text { N1-3/N0 }\end{array}$ & 2.375 & $1.357-4.167$ & 0.003 \\
\hline
\end{tabular}

NSCLC, non-small-cell lung cancer; GPR87, G protein-coupled receptor 87 ; CI, confidence interval; $\mathrm{HR}$, hazard ratio.

Table III. Multivariate Cox proportional hazard regression analysis for predicting survival of the 123 NSCLC patients.

\begin{tabular}{lccc}
\hline Variable & HR & $95 \%$ CI & P-value \\
\hline $\begin{array}{l}\text { GPR87 status } \\
\text { Positive/negative }\end{array}$ & 2.053 & $1.134-3.717$ & 0.018 \\
$\begin{array}{l}\text { Tumor status } \\
\text { T2-4/T1 }\end{array}$ & 2.693 & $1.424-5.096$ & 0.002 \\
$\begin{array}{l}\text { Nodal status } \\
\text { N1-3/N0 }\end{array}$ & 2.294 & $1.299-4.049$ & 0.004 \\
\hline
\end{tabular}

NSCLC, non-small-cell lung cancer; GPR87, G protein-coupled receptor 87 ; $\mathrm{CI}$, confidence interval; $\mathrm{HR}$, hazard ratio.

The apoptotic index varied significantly among the 123 NSCLCs (mean, 19.0; 19.7 $\pm 11.2 \%$ ). However, there was no difference in the apoptotic index between GPR87-positive and GPR87-negative tumors (19.8 \pm 9.8 vs. $19.6 \pm 12.5 \%, \mathrm{P}=0.0916$; Fig. 2D).

Overall survival of NSCLC patients in association with the GPR87 status. The 5-year survival rate was $72.4 \%$ in patients with GPR87-negative and 53.5\% in those with GPR87-positive tumors, with the overall survival being significantly lower in patients with GPR87-positive tumors ( $\mathrm{P}=0.029$, Fig. 3A). In particular, the overall survival was significantly lower in patients with GPR87-positive compared to those with GPR87-negative adenocarcinomas ( 84.1 vs. $62.4 \%, \mathrm{P}=0.024$ ) (Fig. 3B). Although the patients with GPR87-positive squamous cell carcinomas exhibited a similar overall survival to the patients with
GPR87-positive adenocarcinomas (52.5\%), the patients with GPR87-negative squamous cell carcinomas did not exhibit a significantly better overall survival (Fig. 3C). The overall survival was lower in patients with GPR87-positive compared to those with GPR87-negative adenosquamous or large-cell carcinomas. However, the patient number was lower and the difference was not statistically significant ( $\mathrm{P}=0.120$, Fig. 3D).

As shown in Table II, the univariate Cox regression analysis in NSCLC patients demonstrated that GPR87 positivity [hazard ratio $(\mathrm{HR})=1.859 ; \mathrm{P}=0.033$ ], tumor status $(\mathrm{HR}=2.812$; $\mathrm{P} \leq 0.001)$ and nodal status $(\mathrm{HR}=2.375 ; \mathrm{P} \leq 0.001)$ were all significant prognostic factors for NSCLC patients. GPR87 expression was also significantly different in a multivariate analysis of the prognostic factors (Table III).

\section{Discussion}

Human GPR87, also referred to as GPR95, was first identified in 2001 through a search for novel GPR-encoding genes using an Expressed Sequence Tag database (7). Human GPR87, which is located on chromosome $3 \mathrm{q} 24$, encodes 358 amino acids and is characterized by a typical seven-transmembrane structure and a consensus site (S/T-X-V) for the binding of PDZ domain-containing proteins. The GPR87 protein is classified as a member of the $\mathrm{P} 2 \mathrm{Y}$ receptor family on the basis of sequence homology and the presence of conserved amino acids that are important for ligand binding and specificity in other P2Y family members (14). GPR87 is a cell surface GPR expressed at low levels in most tissues, with the exception of prostate, placenta and head and neck tissues. By contrast, GPR87 is highly expressed in squamous cell carcinomas located in the lung, cervix, skin, urinary bladder, testis, head and neck and in large-cell carcinomas and adenocarcinomas of the lung and transitional cell carcinomas of the urinary bladder $(9,15)$. Suggested potential ligands for GPR87 include UDP-glucose and cysteinyl-leukotrienes and, most recently, lysophosphatidic acid (8).

As regards GPR87 expression, studies were mainly performed on cell lines and few clinical samples. To the best of our knowledge, the present study is the first large-scale clinical study on GPR87 expression in human malignant tumors to investigate its association with prognosis and clinical characteristics. In the present study, GPR87 exhibited tumor-specific expression in NSCLCs. Among the 123 NSCLCs investigated, 63 (51.2\%) were GPR87-positive and were more frequently encountered among squamous cell carcinomas, rather than among adenocarcinomas $(\mathrm{P}=0.044)$. This finding is consistent with those of previous studies on NSCLC $(9,15)$. GPR87-positive tumors accounted for $42.9 \%$ of adenosquamous carcinomas (3/7) and $100 \%$ of large-cell carcinomas (2/2). Furthermore, significantly more GPR87-positive tumors were poorly and moderately differentiated rather than well differentiated $(\mathrm{P}=0.029)$.

Although the physiological function of GPR87 has not yet been fully elucidated, GPR 87 has been reported to contribute to the viability of human tumor cells (9) and as being necessary for p53-dependent cell survival in response to genotoxic stress (10). Regarding the biological properties of GPR87 in NSCLC, the present study demonstrated that GPR87 expression was correlated with tumor proliferation. The Ki-67 proliferation index was significantly higher in GPR87-positive compared to that in 
GPR87-negative tumors, which was consistent with the findings of a recent study on bladder carcinoma (16). Furthermore, with the use of serial sections, the Ki-67 immunostaining pattern was found to be immunohistochemically identical to that of GPR87 in the majority of the tumor samples (Fig. 1). These findings suggest that GPR87 expression may play an important role in regulating cell proliferation in NSCLCs. By contrast, regarding apoptosis, no correlation was observed between GPR87 expression and the apoptotic index in NSCLCs.

The overall survival was significantly lower in patients with GPR87-positive compared to those with GPR87-negative NSCLCs. In particular, the overall survival was significantly lower in patients with GPR87-positive adenocarcinomas. Furthermore, the overall survival was lower in patients with GPR87-positive adenosquamous or large-cell carcinomas compared to those with GPR87-negative tumors (Fig. 3D). Although the overall survival of patients with GPR87-positive squamous cell carcinomas was similar to that of patients with GPR87-positive adenocarcinomas, there was no significant difference in survival between patients with GPR87-negative and those with GPR87-positive squamous cell carcinomas, as was the case for patients with non-squamous cell carcinomas. However, the univariate and multivariate Cox regression analyses revealed that the GPR87 expression status was a critical factor predictive of survival in NSCLC patients. To the best of our knowledge, the present study was the first to identify a correlation between GPR87 expression and clinical outcome in patients with malignant tumors, suggesting that GPR87 is an independent prognostic factor for lung cancer.

The recent inconsistency of GPR87 expression in predicting the survival of patients with squamous cell and those with non-squamous cell carcinomas may be attributable to the differences in the molecular etiology of these histological types (17). For example, among NSCLC tumors, the frequency of p53 mutations is the highest in squamous cell carcinomas, whereas it is lower in adenocarcinomas (18-20). Mitsudomi et al (21) reported p53 alterations to be a significant predictor of poor outcome in patients with adenocarcinoma, but not in those with squamous cell carcinoma. These findings suggest that p53 alterations in adenocarcinoma may have a different role from that in squamous cell carcinoma, i.e., a p53 alteration is required for squamous carcinogenesis, whereas it plays a significant role in the malignant progression of adenocarcinoma (21). There is currently little information available on the regulation of GPR87 expression (22). It was demonstrated that GPR87 expression was upregulated in a p53-dependent manner via a p53-responsive element in the GPR87 gene in response to genotoxic stress (10). Therefore, in the presence of p53 alterations, the tumors may not exhibit high GPR87 expression and even patients with GPR87-negative squamous cell carcinoma may exhibit poor survival. Further studies are required to elucidate the association between GPR87 and p53 in NSCLC.

The present study on NSCLCs revealed that the overexpression of GPR87 is significantly associated with poorer differentiation and high proliferation and the GPR87 expression status was identified as a significant prognostic factor for NSCLC patients. As GPR87 is located on the cell surface, its knockdown with either siRNA or antibody may be easily performed. Therefore, GPR87 undoubtedly bears potential as a novel target for cancer prognostication and treatment.

\section{Acknowledgements}

This study was partly supported by Grant-in-Aid for Scientific Research from the Japanese Society for the Promotion of Science (no. 25462179, D. L.).

\section{References}

1. Jemal A, Siegel R, Ward E, Hao Y, Xu J and Thun MJ: Cancer statistics, 2009. CA Cancer J Clin 59: 225-249, 2009.

2. Jackman DM, Miller VA, Cioffredi LA, et al: Impact of epidermal growth factor receptor and KRAS mutations on clinical outcomes in previously untreated non-small cell lung cancer patients: results of an online tumor registry of clinical trials. Clin Cancer Res 15: 5267-5273, 2009.

3. Fredriksson R, Lagerstrom MC, Lundin LG and Schioth HB: The G-protein-coupled receptors in the human genome form five main families. Phylogenetic analysis, paralogon groups, and fingerprints. Mol Pharmacol 63: 1256-1272, 2003.

4. Pierce KL, Premont RT and Lefkowitz RJ: Seven-transmembrane receptors. Nat Rev Mol Cell Biol 3: 639-650, 2002.

5. Dorsam RT and Gutkind JS: G-protein-coupled receptors and cancer. Nat Rev Cancer 7: 79-94, 2007.

6. Nonaka Y, Hiramoto T and Fujita N: Identification of endogenous surrogate ligands for human P2Y12 receptors by in silico and in vitro methods. Biochem Biophys Res Commun 337: 281-288, 2005.

7. Wittenberger T, Schaller HC and Hellebrand S: An expressed sequence tag (EST) data mining strategy succeeding in the discovery of new G-protein coupled receptors. J Mol Biol 307: 799-813, 2001.

8. Tabata K, Baba K, Shiraishi A, Ito M and Fujita N: The orphan GPCR GPR87 was deorphanized and shown to be a lysophosphatidic acid receptor. Biochem Biophys Res Commun 363: 861-866, 2007.

9. Glatt S, Halbauer D, Heindl S, et al: hGPR87 contributes to viability of human tumor cells. Int J Cancer 122: 2008-2016, 2008.

10. Zhang Y, Qian Y, Lu W and Chen X: The G protein-coupled receptor 87 is necessary for p53-dependent cell survival in response to genotoxic stress. Cancer Res 69: 6049-6056, 2009.

11. Goldstraw P, Crowley J, Chansky K, et al; International Association for the Study of Lung Cancer International Staging Committee: The IASLC Lung Cancer Staging Project: proposals for the revision of the TNM stage groupings in the forthcoming (seventh) edition of the TNM Classification of malignant tumours. J Thorac Oncol 2: 706-714, 2007.

12. Nakano J, Huang C, Liu D, et al: Evaluations of biomarkers associated with 5-FU sensitivity for non-small-cell lung cancer patients postoperatively treated with UFT. Br J Cancer 95: 607-615, 2006.

13. Sgonc R and Wick G: Methods for the detection of apoptosis. Int Arch Allergy Immunol 105: 327-332, 1994.

14. Lee DK, Nguyen T, Lynch KR, et al: Discovery and mapping of ten novel G protein-coupled receptor genes. Gene 275: 83-91, 2001.

15. Gugger M, White R, Song S, et al: GPR87 is an overexpressed G-protein coupled receptor in squamous cell carcinoma of the lung. Dis Markers 24: 41-50, 2008.

16. Okazoe H, Zhang X, Liu D, et al: Expression and role of GPR87 in urothelial carcinoma of the bladder. Int J Mol Sci 14: 12367-12379, 2013.

17. Johnson JL, Pillai S and Chellappan SP: Genetic and biochemical alterations in non-small cell lung cancer. Biochem Res Int 2012: 940405, 2012.

18. Tammemagi MC, McLaughlin JR and Bull SB: Meta-analyses of p53 tumor suppressor gene alterations and clinicopathological features in resected lung cancers. Cancer Epidemiol Biomarkers Prev 8: 625-634, 1999.

19. Kishimoto Y, Murakami Y, Shiraishi M, Hayashi K and Sekiya T: Aberrations of the $\mathrm{p} 53$ tumor suppressor gene in human non-small cell carcinomas of the lung. Cancer Res 52: 4799-4804, 1992.

20. Mogi A and Kuwano H: TP53 mutations in nonsmall cell lung cancer. J Biomed Biotechnol 2011: 583929, 2011.

21. Mitsudomi T, Hamajima N, Ogawa M and Takahashi T: Prognostic significance of p53 alterations in patients with non-small cell lung cancer: a meta-analysis. Clin Cancer Res 6: 4055-4063, 2000.

22. Zhang Y, Scoumanne A and Chen X: G protein-coupled receptor 87: a promising opportunity for cancer drug discovery. Mol Cell Pharmacol 2: 111-116, 2010. 